\title{
Surface requirements for optimal biosensing with disposable gold electrodes
}

Marjon Zamani, ${ }^{1}$ Victoria Yang, ${ }^{1}$ Lizi Maziashvili, ${ }^{1}$ Gang Fan, ${ }^{1}$ Catherine M. Klapperich, ${ }^{2}$ Ariel L. Furst ${ }^{1,3, *}$

${ }^{1}$ Department of Chemical Engineering, Massachusetts Institute of Technology, Cambridge, Massachusetts 02139, United States

${ }^{2}$ Department of Biomedical Engineering, Boston University, Boston, Massachusetts 02215, United States

${ }^{3}$ Center for Environmental Health Sciences, Massachusetts Institute of Technology, Cambridge, Massachusetts 02139, United States

\section{Supplemental Information}

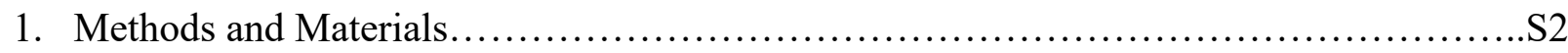

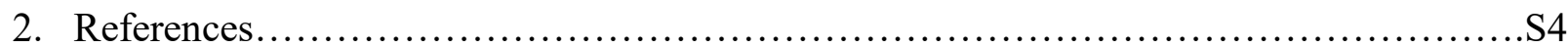




\section{Methods and Materials}

Imaging

Atomic force microscopy (AFM) was performed using an NT-MDT microscope with cantilevers from $\mu$ masch (HQ:NSC16/A1BS) Scanning electron microscopy (SEM) was performed with a Zeiss Merlin high-resolution scanning electron microscope (Jena, Germany) with an accelerating voltage of $1 \mathrm{kV}$ (with a resolution of $1.4 \mathrm{~nm}$ ). A typical pin stub mount was made of aluminum attached to a gold electrode substrate using carbon conducting tape and silver paste prior to SEM analysis

\section{Electrochemistry: Instrumentation}

All data was collected with a Gamry Reference $600+$ potentiostat. Pretreatment was performed with either a Gamry Reference 600+, a Squidstat (Admiral Instruments) or a Biologic VMP-300 potentiostat.

\section{Electrode fabrication}

Commercial SPEs (DRP-220AT, DRP-220BT) were purchased from Metrohm. Gold leaf electrodes were fabricated according to a previously-established protocol. ${ }^{1}$

\section{Electroactive surface area determination and functionalization}

Electrodes were cleaned using a standard protocol by performing cyclic voltammetry in $0.5 \mathrm{M}$ $\mathrm{H}_{2} \mathrm{SO}_{4}$. During cleaning, the electroactive surface area of the electrodes could be evaluated by integrating the reductive peak of the $10^{\text {th }}$ scan of the bare electrode in $0.5 \mathrm{M} \mathrm{H}_{2} \mathrm{SO}_{4}$. The potential was cycled between $-0.1 \mathrm{~V}$ and $1.1 \mathrm{~V}-1.5 \mathrm{~V} 100 \mathrm{mV} / \mathrm{sec}$ vs. a pseudoreference. The area of the reductive peak was converted to electroactive surface area using the standard conversion factor $386 \mu \mathrm{C} / \mathrm{cm}^{2}{ }^{2}$

Electrodes were functionalized with methylene blue (MB)- tagged oligonucleotides according to a previously established protocol. ${ }^{1}$ Following TCEP reduction, $0.4 \mu \mathrm{M}$ of oligonucleotide was deposited on the on the electrode in $125 \mathrm{mM}$ Tris, $740 \mathrm{mM} \mathrm{NaCl}$, $\mathrm{pH} 8.5$ for $2 \mathrm{~h}$. Electrodes were then back-filled with $1 \mathrm{mM}$ 6-mercapto-1-hexanol for 1 hour. Square wave voltammetry was performed in $20 \mathrm{mM}$ Tris buffer, $20 \mathrm{mM} \mathrm{NaCl}, \mathrm{pH} 7.0$; the electrodes were scanned from $-0.5 \mathrm{~V}$ to $-0.05 \mathrm{~V}$ with a step size of $4 \mathrm{mV}$, a frequency of $15 \mathrm{~Hz}$ and a pulse size of $25 \mathrm{mV}$.

\section{DNA quantification}

Oligonucleotides deposited on the electrodes were quantified with hexaamineruthenium (III) chloride (Ruhex) (Sigma, 262005). $50 \mu \mathrm{M}$ of Ruhex in $10 \mathrm{mM}$ Tris-Cl buffer, pH 8.5 was deposited on the electrodes at ambient temperature. The electrodes were then rinsed twice with $200 \mu \mathrm{L}$ of $10 \mathrm{mM}$ Tris-Cl buffer, $\mathrm{pH}$ 8.5. Cyclic voltammetry was performed in $10 \mathrm{mM}$ Tris-Cl, $\mathrm{pH}$ 8.5. The potential was scanned from $-0.5 \mathrm{~V}$ to $0.0 \mathrm{~V}$ at $100 \mathrm{mV} / \mathrm{sec}$. The area under the oxidative peak was integrated to determine the total charge. The surface coverage of DNA at the electrodes was calculated using Equation 1:

$$
\mathrm{SC}=\frac{Q}{9 n F A}
$$


Where SC = surface coverage, $\mathrm{Q}=$ Ruhex charge, $\mathrm{n}=$ the number of electrons transferred during a redox event, $\mathrm{F}=$ faraday's constant and $\mathrm{A}=$ electroactive surface area of the electrodes. The factor of 9 was included to account for the charge of the Ruhex based on the number of DNA bases (27/3). At least three biological replicates were performed for each experiment.

DNase I Assay

DNase I (Sigma, DN25) in $10 \mathrm{mM}$ Tris-HCl, $2.5 \mathrm{mM} \mathrm{MgCl}_{2}, 0.5 \mathrm{mM} \mathrm{CaCl}_{2}, \mathrm{pH} 7.6$ was incubated on functionalized electrodes for $1 \mathrm{~h}$ at $37^{\circ} \mathrm{C}$. The electrodes were rinsed with $20 \mathrm{mM}$ Tris buffer, $20 \mathrm{mM} \mathrm{NaCl}$, pH 7.0 before being measured again. The ratio of the MB signal after DNase I treatment to before was calculated for each electrode. At least three biological replicates were performed for each experiment. 


\section{References}

(1) Zamani, M.; Robson, J. M.; Fan, A.; Bono, M. S.; Furst, A. L.; Klapperich, C. M. Electrochemical Strategy for Low-Cost Viral Detection. ACS Cent. Sci. 2021, 7 (6), 963972. https://doi.org/10.1021/acscentsci.1c00186.

(2) Burke, L. D.; Nugent, P. F. The Electrochemistry of Gold: I. The Redox Behaviour of the Metal in Aqueous Media. Gold Bull. 1997, 30 (2), 43-53.

https://doi.org/10.1007/BF03214756. 